\title{
Cyclodextrin-Mediated Deacylation of Amino Acid Esters with Marked Stereoselectivity
}

\author{
Koichi Goto,${ }^{a}$ Kentaro Nakashima, ${ }^{a}$ Osamu Tanoue, ${ }^{a}$ Satoshi Nukushina, ${ }^{a}$ Isao Toudo, ${ }^{a}$ \\ Chikara Imamura, ${ }^{b}$ Yasuji Ihara, ${ }^{b}$ Yoko Matsumoto, ${ }^{a}$ and Ryuichi UeokA ${ }^{*, a}$ \\ ${ }^{a}$ Division of Applied Chemistry, Graduate School of Sojo University (former name: Kumamoto Institute of Technology); \\ 4-22-1 Ikeda, Kumamoto 860-0082, Japan: and ${ }^{b}$ Department of Human Environment, Yamaguchi Prefectural University; \\ 3-2-1 Sakurabatake, Yamaguchi 753-8502, Japan. \\ Received May 1, 2002; accepted June 28, 2002; published online July 3, 2002
}

\begin{abstract}
With respect to the hydrolysis (deacylation) of $Z$-D(L)-amino acid esters ( $N$-(benzyloxycarbonyl)-D(L)-amino acid $p$-nitrophenyl esters) mediated by $\alpha$-, $\beta$ - and $\gamma$-cyclodextrins (CyDs), a remarkably high enantioselectivity $(\mathrm{L} / \mathrm{D}=9.0)$ was observed for the deacylation of Ala substrate with $\gamma$-CyD. The kinetic results on the basis of the Michaelis-Menten principle indicate that the enantioselectivity should be mainly originated in the deacylation process of substrates following the formation of $\gamma$-CyD-substrate $(1: 1)$ complexes. The computer modeling (molecular mechanics) studies on the inclusion complexes are also described.
\end{abstract}

Key words cyclodextrin; enantioselective hydrolysis; amino acid ester

Stereoselective hydrolysis of amino acid esters have attracted considerable attention in connection with understanding the origins of the stereoselectivity observed with proteolytic enzymes. In the course of our study on the enantioselective hydrolysis (deacylation) of amino acid esters with the functional molecular assemblies composed of surfactants and reactive species, we emphasized that the stereochemical control could be attained by changing the composition of the coaggregates $^{1-4)}$ and regulating ionic strength ${ }^{5,6)}$ and temperature. ${ }^{7,8)}$

Furthermore, since cyclodextrins (CyDs) have been noted as useful enzyme mimics, ${ }^{9-12)}$ we employed CyDs as host molecules and a markedly high stereoselectivity was attained in the diastereoselective deacylation of dipeptide esters. ${ }^{13)} \mathrm{On}$ the other hand, Ueno reported the high D-enantiomer-selective deacylation of amino acid esters mediated by modified $\beta$-CyDs. ${ }^{14)}$ However, little has been known about the significant enantioselectivity for the deacylation of amino acid esters with unmodified CyDs. ${ }^{15)}$

In this study, we report the successful experimental results with marked enantioselectivity for the deacylation of $Z$-D(L)amino acid esters ( $N$-(benzyloxycarbonyl)-D(L)-amino acid $p$ nitrophenyl esters) as mediated by unmodified CyDs, and the computer modeling (molecular mechanics) studies on the inclusion complexes of $\gamma$-CyD with the specific substrates are also presented.

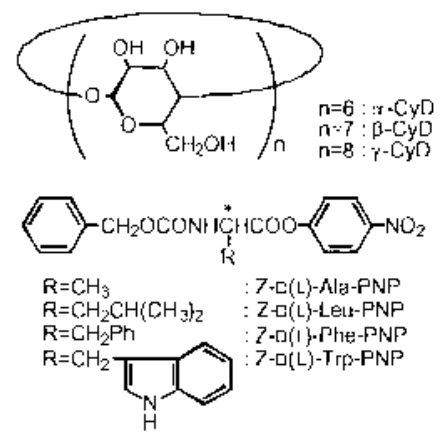

Fig. 1. Cyclodextrins (CyDs) and Z-D(L)-Amino Acid Esters

\section{Results and Discussion}

With respect to the enantioselective hydrolysis (deacylation) of $Z$-D(L)-amino acid esters (Z-D(L)-Ala, Leu, Phe and Trp-PNP) mediated by unmodified $\alpha$-, $\beta$ - and $\gamma$-CyDs, the kinetic parameters obtained on the basis of the MichaelisMenten principle, the binding constant $\left(K_{\mathrm{b}}\right)$ for the formation of CyD-substrate complex and the rate constant $\left(k_{2}\right)$ for the deacylation of substrate by CyD, are summarized in Table $1-3$. The noteworthy aspects are as follows: (a) Overall, the deacylation mediated by $\alpha$-CyD was favorable for all of the L-enantiomeric substrates (reflected in $k_{2} K_{\mathrm{b}}, \mathrm{L} / \mathrm{D}=1.5-1.7$ ), though the $K_{\mathrm{b}}$ for D-isomer of Phe substrate and $k_{2}$ values for D-isomer of Ala substrate were larger than those for the corresponding $\mathrm{L}$-isomers. (b) In the case of the reaction by $\beta$ CyD, L-enantiomer-selectivity was also observed for the deacylation of Ala, Leu and Phe substrates ( $\mathrm{L} / \mathrm{D}=1.5-3.2)$, while $D$-enantiomeric selectivity $(\mathrm{D} / \mathrm{L}=1.4)$ was observed for the deacylation of Trp substrate. (c) Relatively higher L-enantioselectivity was obtained in the deacylation mediated by $\gamma$ $\mathrm{CyD}(\mathrm{L} / \mathrm{D}=2.6-9.0)$. Most remarkably, the highest enantioselectivity $(L / D=9.0)$ was attained for the deacylation of Ala substrate. Furthermore, it was also attractive that this fairly high enantioselectivity $(\mathrm{L} / \mathrm{D}=9.0)$ could be mainly originated in the deacylation process of substrates, because it was reflected by a fairly large $k_{2}^{\mathrm{L}} / k_{2}^{\mathrm{D}}$ value (7.4) and a small $K_{\mathrm{b}}^{\mathrm{L}} / K_{\mathrm{b}}^{\mathrm{D}}$ (1.2).

On the other hand, Table 4 shows the results of energies for the inclusion complexes on Z-D(L)-Ala-PNP having different shapes with $\gamma$-CyD calculated by molecular mechanics with water solvent effects. It was suggested that the conformation of a hairpin shape (Fig. 2a) should be more favorable as compared with the straight shape (Fig. 2b) for the inclusion complex on D- or L-isomer and $\gamma$-CyD. Furthermore, the energy of the inclusion complex with L-isomer was lower than that with D-isomer, which is in harmony with the $K_{\mathrm{b}}$ value $(\mathrm{L} / \mathrm{D}=1.2)$ for the binding process on $Z$ - $\mathrm{D}(\mathrm{L})$-Ala-PNP and $\gamma$-CyD. Therefore, it was estimable that $Z$-D(L)-Ala-PNP having a hairpin shape was encapsulated by $\gamma-\mathrm{CyD}$ as in Fig. 3. Plausibly, the complex between $\gamma$-CyD and L-isomer having a hairpin shape should be more efficient for the next dea- 
Table 1. Kinetic Parameters for the Deacylation of Z-D(L)-Amino Acid $p$-Nitrophenyl Esters Mediated by $\alpha$-CyD

\begin{tabular}{|c|c|c|c|c|c|c|c|c|c|c|}
\hline \multirow{2}{*}{ Substrate } & \multirow{2}{*}{$k_{\mathrm{s}}\left(\mathrm{s}^{-1}\right)$} & \multicolumn{2}{|c|}{$k_{2}\left(\mathrm{~s}^{-1}\right)$} & \multirow{2}{*}{ L/D } & \multicolumn{2}{|c|}{$K_{\mathrm{b}}\left(\mathrm{M}^{-1}\right)$} & \multirow{2}{*}{ L/D } & \multicolumn{2}{|c|}{$k_{2} K_{\mathrm{b}}\left(\mathrm{M}^{-1} \mathrm{~s}^{-1}\right)$} & \multirow{2}{*}{$\mathrm{L} / \mathrm{D}$} \\
\hline & & L-Isomer & D-Isomer & & L-Isomer & D-Isomer & & L-Isomer & D-Isomer & \\
\hline Z-Ala-PNP & 0.00291 & 0.0947 & 0.166 & $1.8(\mathrm{D} / \mathrm{L})$ & 1.99 & 0.778 & 2.6 & 0.188 & 0.129 & 1.5 \\
\hline$Z$-Leu-PNP & 0.00155 & 0.0118 & 0.0112 & 1.1 & 11.2 & 4.99 & 1.4 & 0.132 & 0.0909 & 1.5 \\
\hline$Z$-Phe-PNP & 0.00419 & 0.106 & 0.0302 & 3.5 & 8.12 & 6.97 & $2.1(\mathrm{D} / \mathrm{L})$ & 0.249 & 0.151 & 1.6 \\
\hline$Z$-Trp-PNP & 0.00215 & 0.0302 & 0.0282 & 1.1 & 2.35 & 4.41 & 1.6 & 0.210 & 0.124 & 1.7 \\
\hline
\end{tabular}

$25^{\circ} \mathrm{C}, \mathrm{pH} 9.5,0.02 \mathrm{M}$ carbonate buffer $(0.05 \mathrm{M} \mathrm{KCl}), 10 \%(\mathrm{v} / \mathrm{v}) \mathrm{CH}_{3} \mathrm{CN}-\mathrm{H}_{2} \mathrm{O}$, [substrate] $=7.0 \times 10^{-6} \mathrm{M},[\alpha-\mathrm{CyD}]=(1.0-10) \times 10^{-3} \mathrm{M}$.

Table 2. Kinetic Parameters for the Deacylation of $Z$-D(L)-Amino Acid $p$-Nitrophenyl Esters Mediated by $\beta$-CyD

\begin{tabular}{|c|c|c|c|c|c|c|c|c|c|c|}
\hline \multirow{2}{*}{ Substrate } & \multirow{2}{*}{$k_{\mathrm{s}}\left(\mathrm{s}^{-1}\right)$} & \multicolumn{2}{|c|}{$k_{2}\left(\mathrm{~s}^{-1}\right)$} & \multirow{2}{*}{$\mathrm{L} / \mathrm{D}$} & \multicolumn{2}{|c|}{$K_{\mathrm{b}}\left(\mathrm{M}^{-1}\right)$} & \multirow{2}{*}{$\mathrm{L} / \mathrm{D}$} & \multicolumn{2}{|c|}{$k_{2} K_{\mathrm{b}}\left(\mathrm{M}^{-1} \mathrm{~s}^{-1}\right)$} & \multirow{2}{*}{$\mathrm{L} / \mathrm{D}$} \\
\hline & & L-Isomer & D-Isomer & & L-Isomer & D-Isomer & & L-Isomer & D-Isomer & \\
\hline Z-Ala-PNP & 0.00291 & 0.140 & 0.154 & $1.1(\mathrm{D} / \mathrm{L})$ & 32.9 & 9.25 & 3.6 & 4.61 & 1.42 & 3.2 \\
\hline Z-Leu-PNP & 0.00155 & 0.0198 & 0.0142 & 1.4 & 124 & 62.5 & 2.0 & 2.45 & 0.888 & 2.8 \\
\hline Z-Phe-PNP $\left.{ }^{a}\right)$ & 0.00419 & 0.109 & 0.0484 & 2.3 & 95.6 & 148 & $1.6(\mathrm{D} / \mathrm{L})$ & 10.4 & 7.16 & 1.5 \\
\hline Z-Trp-PNP & 0.00215 & 0.112 & 0.124 & $1.1(\mathrm{D} / \mathrm{L})$ & 86.9 & 114 & $1.3(\mathrm{D} / \mathrm{L})$ & 9.73 & 14.1 & $1.4(\mathrm{D} / \mathrm{L})$ \\
\hline
\end{tabular}

$25^{\circ} \mathrm{C}, \mathrm{pH} 9.5,0.02 \mathrm{M}$ carbonate buffer $(0.05 \mathrm{M} \mathrm{KCl}), 10 \%(\mathrm{v} / \mathrm{v}) \mathrm{CH}_{3} \mathrm{CN}-\mathrm{H}_{2} \mathrm{O}$, [substrate $\left.]=7.0 \times 10^{-6} \mathrm{M},[\beta-\mathrm{CyD}]=(1.0-10) \times 10^{-3} \mathrm{M} . a\right)[\beta-\mathrm{CyD}]=(0.10-10) \times 10^{-3} \mathrm{M}$.

Table 3. Kinetic Parameters for the Deacylation of Z-D(L)-Amino Acid $p$-Nitrophenyl Esters Mediated by $\gamma$-CyD

\begin{tabular}{|c|c|c|c|c|c|c|c|c|c|c|}
\hline \multirow{2}{*}{ Substrate } & \multirow{2}{*}{$k_{\mathrm{s}}\left(\mathrm{s}^{-1}\right)$} & \multicolumn{2}{|c|}{$k_{2}\left(\mathrm{~s}^{-1}\right)$} & \multirow{2}{*}{$\mathrm{L} / \mathrm{D}$} & \multicolumn{2}{|c|}{$K_{\mathrm{b}}\left(\mathrm{M}^{-1}\right)$} & \multirow{2}{*}{$\mathrm{L} / \mathrm{D}$} & \multicolumn{2}{|c|}{$k_{2} K_{\mathrm{b}}\left(\mathrm{M}^{-1} \mathrm{~s}^{-1}\right)$} & \multirow{2}{*}{ L/D } \\
\hline & & L-Isomer & D-Isomer & & L-Isomer & D-Isomer & & L-Isomer & D-Isomer & \\
\hline Z-Ala-PNP & 0.00291 & 0.264 & 0.0357 & 7.4 & 101 & 83.4 & 1.2 & 26.7 & 2.98 & 9.0 \\
\hline$Z$-Leu-PNP & 0.00155 & 0.0827 & 0.0146 & 5.7 & 147 & 121 & 1.2 & 12.2 & 1.77 & 6.9 \\
\hline Z-Phe-PNP & 0.00419 & 0.171 & 0.0529 & 3.2 & 171 & 89.2 & 1.9 & 29.2 & 4.72 & 6.2 \\
\hline Z-Trp-PNP & 0.00215 & 0.0957 & 0.0384 & 2.5 & 109 & 105 & 1.0 & 10.4 & 4.03 & 2.6 \\
\hline
\end{tabular}

$25^{\circ} \mathrm{C}, \mathrm{pH} 9.5,0.02 \mathrm{M}$ carbonate buffer $(0.05 \mathrm{M} \mathrm{KCl}), 10 \%(\mathrm{v} / \mathrm{v}) \mathrm{CH}_{3} \mathrm{CN}-\mathrm{H}_{2} \mathrm{O}$, [substrate $]=7.0 \times 10^{-6} \mathrm{M},[\gamma-\mathrm{CyD}]=(1.0-10) \times 10^{-3} \mathrm{M}$.

Table 4. Energies on the Basis of Molecular Mechanics Calculations for the Inclusion Complexes on Z-D(L)-Ala-PNP Having Different Shapes with $\gamma$-CyD in Water

\begin{tabular}{ccc}
\hline \hline & \multicolumn{2}{c}{ Inclusion complex energy $(\mathrm{kJ} / \mathrm{mol})$} \\
\cline { 2 - 3 } & Hairpin shape & Straight shape \\
\hline L-Isomer & 254.70 & 262.42 \\
D-Isomer & 261.78 & 274.99 \\
\hline
\end{tabular}

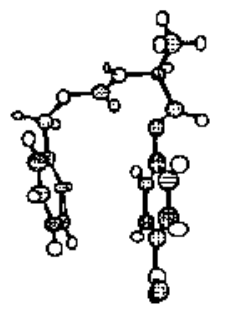

[a]

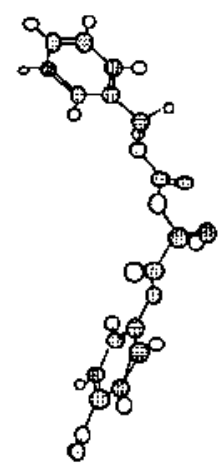

ib)

Fig. 2. Calculated Stable Structures of Hairpin Shape (a) and Straight Shape (b) on Z-L-Ala-PNP

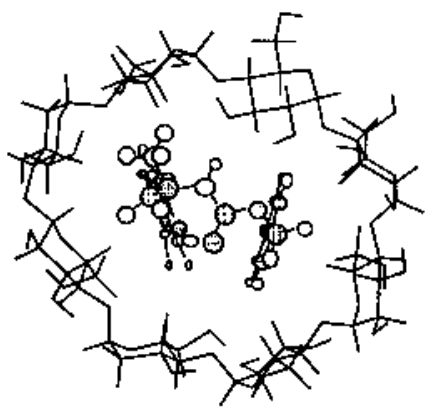

top view

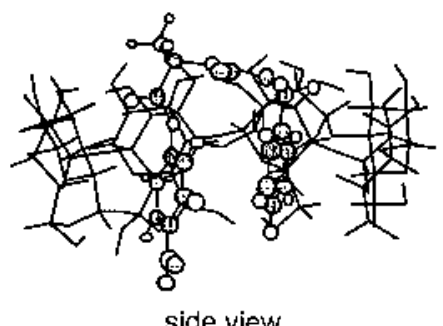

Fig. 3. The Calculated Stable Structures of Inclusion Complex on $Z$-LAla-PNP with $\gamma$-CyD 
cylation step as compared with that between $\gamma$-CyD and the corresponding D-isomer. More detailed modeling studies are being continued in order to gain further insight into the origin of the marked enantioselectivity.

In conclusion, the remarkably high enantioselectivity $(\mathrm{L} / \mathrm{D}=9.0)$ was observed for the hydrolysis (deacylation) of $Z$ $\mathrm{D}(\mathrm{L})$-Ala-PNP mediated by unmodified $\gamma$-CyD for the first time. The kinetic results on the basis of the MichaelisMenten principle indicate that this L-superior enantioselectivity should be mainly originated in the deacylation process of substrates following the formation of $\gamma$-CyD-substrate $(1: 1)$ complexes. The computer modeling (molecular mechanics) studies supported the L enantioselectivity on the formation of inclusion complex with the more stable conformer of the guest.

\section{Experimental}

Materials The ester substrates were prepared from $N$-(benzyloxycarbonyl)-D(or L)-amino acids by the esterification of the $\mathrm{COOH}$ group with $p$ nitrophenol and dicyclohexylcarbodiimide as described in ref 1 . These enantiomeric isomers were fully characterized. Commercially available $\alpha-, \beta$ and $\gamma$-CyDs were recrystallized from deionized water and dried in vacuum at $40^{\circ} \mathrm{C}$ for $24 \mathrm{~h}$

Kinetic Measurements Under the conditions [CyD] $\gg$ [substrate], pseudo-first-order rate constants ( $k_{\mathrm{t}}$ in the presence of CyD and $k_{\mathrm{s}}$ in the absence of $\mathrm{CyD}$ ) for the deacylation of amino acid esters were evaluated from monitoring $p$-nitrophenolate liberation from the esters at $400 \mathrm{~nm}$. The stoichiometry for the complexation of CyDs and substrates could not be confirmed by spectroscopic examinations $\left({ }^{1} \mathrm{H}-\mathrm{NMR}\right.$, UV and fluorescence measurements). It was assumed that the reaction proceeds via the formation of $1: 1$ complex as shown in eq 1 , and the $K_{\mathrm{b}}\left(=k_{1} / k_{-1}\right)$ and $k_{2}$ values were determined by the least-squares method from Lineweaver-Burk plots between $1 /\left(k_{\mathrm{t}}-k_{\mathrm{s}}\right)$ and $1 /[\mathrm{CyD}]$ in eq 2 (correlation coefficients for the plots were $>0.994)$ as described in ref 16 .

$$
\mathrm{CyD}+\mathrm{S} \underset{k_{-1}}{\stackrel{k_{1}}{\longrightarrow}} \mathrm{CyD}-\mathrm{S} \stackrel{k_{2}}{\longrightarrow} \text { acyl-CyD + products, } \mathrm{S} \stackrel{k_{s}}{\longrightarrow} \text { products }
$$

$$
1 /\left(k_{\mathrm{t}}-k_{\mathrm{s}}\right)=1 /\left(k_{2}-k_{\mathrm{s}}\right)+1 /\left\{K_{\mathrm{b}}\left(k_{2}-k_{\mathrm{s}}\right)[\mathrm{CyD}]\right\}
$$

Calculation Method Conformer search for the structures of $Z$-D(L)-AlaPNP and the inclusion complex with $\gamma$-CyD was performed on the basis of Monte Carlo method in conjunction with $\mathrm{MMFF}^{17-19)}$ molecular mechanics. Two minimum energy conformers of $Z$-D(L)-Ala-PNP were found, one had a hairpin shape with the $p$-nitrophenyl group located parallel to the $Z$ group and the other had a straight shape with the $p$-nitrophenyl and $Z$ groups located in opposite directions. These conformers of Z-D(L)-Ala-PNP were placed in the center of the cavity of $\gamma-\mathrm{CyD}$, and the most stable structures of the inclusion complex were searched in order to obtain the starting geome- tries for the molecular mechanics calculations with water solvent effects. The molecular mechanics calculations were performed by the conjugate gradient algorithm with OPLS all atom force fields ${ }^{20)}$ as implemented in MacroModel 7.1. ${ }^{21)}$ All of the calculations were carried out under the condition of Max Iteration $=10000$ steps, Converge Threshold $=0.0010$. Solvation was achieved by using GB/SA solvation model ${ }^{22)}$ inside MacroModel 7.1. Furthermore, preliminary calculations for the formation of the intermediates in deacylation process have been attempted by the molecular dynamics and molecular mechanics methods.

\section{References and Notes}

1) Ueoka R., Matsumoto Y., Moss R. A., Sugii A., Harada K., Kikuchi J., Murakami Y., J. Am. Chem. Soc., 110, 1588-1595 (1988).

2) Goto K., Matsumoto Y., Ueoka R., J. Org. Chem., 60, 3342-3346 (1995).

3) Ueoka R., Moss R. A., Swarup S., Matsumoto Y., Strauss G., Murakami Y., J. Am. Chem. Soc., 107, 2185-2186 (1985).

4) Ueoka R., Dozono H., Matsumoto Y., Moss R. A., Cho M., Kitahara K., Kato Y., Chem. Pharm. Bull., 38, 219-220 (1990).

5) Tanoue O., Baba M., Tokunaga Y., Goto K., Matsumoto Y., Ueoka R., Tetrahedron Lett., 40, 2129-2132 (1999).

6) Ueoka R., Cho M., Matsumoto Y., Goto K., Kato Y., Harada K., Sugii A., Tetrahedron Lett., 31, 5335-5338 (1990).

7) Matsumoto Y., Ueoka R., J. Org. Chem., 55, 5797-5799 (1990).

8) Ueoka R., Yamada E., Yamashita O., Matsumoto Y., Kato Y., Tetrahedron Lett., 32, 6597-6600 (1991).

9) Komiyama M., Bender M. L., J. Am. Chem. Soc., 100, 4576-4579 (1978).

10) Trainor G. L., Breslow R., J. Am. Chem. Soc., 103, 154-158 (1981).

11) Ueno A., Moriwaki F., Osa T., Ikeda T., Toda F., Hattori K., Bull. Chem. Soc. Jpn., 59, 3109-3112 (1986).

12) Kitaura Y., Bender M. L., Bioorg. Chem., 4, 237-249 (1975).

13) Ueoka R., Matsumoto Y., Harada K., Akahoshi H., Kato Y., J. Am. Chem. Soc., 114, 8339-8340 (1992).

14) Hamasaki K., Ueno A., Chem. Lett., 1995, 859-860.

15) Ihara Y., Nakanishi E., Nango M., Koga J., Bull. Chem. Soc. Jpn., 59, 1901-1905 (1986).

16) Taniguchi Y., Makimoto S., Suzuki K., J. Phys. Chem., 85, 34693472 (1981).

17) Halgren T. A., J. Comp. Chem., 17, 490-519, 520-552, 553-586, 616-641 (1996).

18) Halgren T. A., Nachbar R. B., J. Comp. Chem., 17, 587-615 (1996).

19) Halgren T. A., J. Comp. Chem., 20, 720-729, 730-748 (1996).

20) Jorgensen W. L., Maxwell D. S., Tirado-Rives J., J. Am. Chem. Soc., 118, 11225-11236 (1996).

21) Mohamadi F., Richards N. G. J., Guida W. C., Liskamp R., Lipton M., Caufield C., Chang G., Hendrickson T., Still W. C., J. Comput. Chem., 11, $440-467$ (1990).

22) Still W. C., Tempczyk A., Hawley R. C., Hendrickson T., J. Am. Chem. Soc., 112, 6127-6129 (1990). 